- We wait with baited breath to learn how many practices will fall short of their UDAs.

Will our worst fears come true?

- What will happen come 2009? Will that be the real Big Bang?

- Year on year, our society gets ever more complex. How will that affect dentistry?

- Can a dentist actually ethically continue to practise dentistry in the NHS, or should we all now leave for the private sector?

\title{
A fistful of UDAs
}

\section{S. Hudson ${ }^{1}$}

One year in and we are now starting to see the truth behind the new contract, which was hailed as the saviour of NHS dentistry. Despite words of comfort and reassurance from the CDO, the majority of dentists seem ill at ease with their lot. There are mutterings in the ranks; there are concerned whispers about UDA values and 2009. They huddle in their surgeries, worrying about the financial implications of their underperformance. PCTs, short of money are only now being given the data by the BSA about how well their dentists have done. Many are not happy with what they see. This article looks at where we are now, and gives a personal view on how we got here.

We recently saw the release of the dental contract monitoring toolkit, which some poor soul at your PCT will have to deal with. This is a fine example of the way the Department of Health sometimes works. It is reactive rather than proactive, as can also be seen by the way the UDA guidelines released by the BSA have been changing. A friend of mine actually wrote to the BSA with a whole list of questions about UDAs (all those questions that weren't answered by those extremely thorough FAQs on the BSA website). The BSA declined to give him a written response to his questions, and phoned him up to answer them. When asked why there was no definitive guidance like the old SDR, the response was that 'dentists have complained for years about the SDR, so we thought this way was better'. I suppose that is a fair enough comment, but now dentists are

${ }^{1}$ Principal dentist and creator of www.GDPResources. com, 2 Crown close, New Whittington, Chesterfield, S43 $2 \mathrm{AH}$

Correspondence to: Dr Stephen Hudson

Email: info@gdpresources.com

\section{Refereed Paper}

Accepted 19 January 2007

DOI: $10.1038 /$ bdj.2007.632

${ }^{\circ}$ British Dental Journal 2007; 203: 71-73 having to interpret these vague new regulations to the best of their ability and thereby risk being accused of fraud, wrongdoing, as well as being seen as a founding member of the 'Axis of Evil' if they get said interpretation wrong. Despite this, we must understand that the BSA are doing the best that they can as they have effectively had this dumped on them, as have the PCTs.

But this is only part of a much bigger picture in my opinion. What we are basically seeing is something reflected in all of today's society, and it is nothing new. As societies grow, and as technological advances occur, society becomes more complex. More information is produced that needs collecting and collating. This requires more management level staff to deal with an ever growing mound of paperwork. More and more people are employed by a government that has to constantly be seen to justify its existence, and has to raise more tax to pay for its ever increasing workforce. Government justifies its existence by passing more and more laws, which require more people to implement them. More people are needed to monitor and enforce said laws, and more people are needed to monitor and appraise the enforcers.
Computerisation actually makes things worse because it allows for the collection and analysis of more data, which requires whole armies of people to collect it and input it, the software for which gets ever more complex and riddled with bugs.

As Parkinson's law states, 'All data expand to fill all available storage space'. Parkinson's law also states 'Unit costs of public services rise to meet the available funds'. It is therefore almost impossible for there to be savings in public finances because this would require people to sacrifice their livelihoods, and would also mean the government facing the politically suicidal accusation of "cutting public services'. So in the absence of true political leadership willing to challenge the status quo (which I doubt we will ever see because the status quo just does not want to be challenged), the level of bureaucracy and your tax bill will go ever upward, while productivity within society shrinks. Jobs in the private sector start to be shipped to regions of the world where there is less complexity (and lower wages) while jobs in the public sector expand.

As society becomes more complex, there is a greater need for specialisation. More and more people end up doing 
less and less work, because each person becomes specialised in 'their field of expertise'. These specialists require highly specialised centres to train them, and this training becomes more refined as technology advances. This all requires money. This is one of the many reasons the NHS is now the world's third largest employer, with a Treasury bill of over $£ 90$ billion. Everything has to be monitored, and everything gets more complex as technology advances. As things get more complex, they get more expensive, and more specialised, which requires more monitoring, which results in an ever expanding vicious circle of useless management. At 23 years old, college graduates get paid three times as much as veteran ward sisters to tell them how to do the job they have been doing damned effectively for the last 25 years.

The exception to this was the old GDS. Fees were cut, and in response, many practitioners felt (wrongly in my opinion) that the only response was to work harder and longer. It was highly productive, but people complained because they felt that they were on a treadmill (partly because they were doing absolutely everything themselves). Unfortunately the treadmill was of their own making. If they had seen fewer patients instead of more (and treated the patients they wanted to see instead of seeing all and sundry) they would have soon found that there were a lot of people out there who wanted highly profitable private dentistry. Dentists would have realised that they didn't have to kill themselves to make a living under the NHS, because the money they lost from reducing their patient numbers was more than made up for by the private fees they collected. But because dentists didn't spend the time, the patients didn't have the chance to tell them that they wanted tooth whitening because the dentists were too busy sheep dipping them. Of course, if all dentists had done this years ago there would have been a crash in the registration figures, and the Government may well have acted sooner, and in a different way. So, as painful as it is to say, the dentists have to share the blame for the present situation.

That is all irrelevant now because we have the UDA. Unlike the GDS where the treadmill was a choice, under the new contract the treadmill is a fact. The UDA puts dentists on the treadmill because many were contracted to do horrendous amounts of work, with no real benefit to themselves or their patients, based on figures which have now been shown to be inaccurate in many cases. The money available is not there to allow dentists to slow down (which was a definite option in the old GDS), and slowing down is now vital. The sad fact is that treadmill style dentistry should no longer be an option. You shouldn't be doing it. You shouldn't even be thinking about doing it. It is unethical, it is unhealthy, it is unwanted and it is unprofitable.

Unfortunately (or fortunately depending on your point of view) the only way off the treadmill now for many practice owners is to enter the private sector. This will happen more and more frequently over the coming years, and it is a good thing. As society becomes more complex, the documentation requirements in all areas become greater. Dentistry is no exception. GDPs are now entering an era where a vast amount of data on each patient is required before treatment is commenced. Data such as:

- Medical History

- Address/D.O.B

- Past dental history

- Full TMJ examination and noting of joint sounds/TMJD

- Soft tissues examination

- Full muscle palpation

- Full occlusal exam, including slides, anterior guidance, working and non working side interferences

- Full periodontal examination and mobility scores

- Noting of wear facets, fremitus, plaque scores, bleeding index etc

- Full record of all preventive advice and $\mathrm{OH}$ education follow up.

All this before you even chart the teeth. You cannot do this if you are hunting UDAs. You cannot do this if you are squeezing greater numbers of patients into your waiting room. This level of clinical recording is now essential, because of another growing specialisation; our old friends the lawyers, who now have specialists in the field of dental litigation. We are, in effect, being forced to provide dentistry to an extremely high standard, and you cannot do this when you are dancing daintily with the UDA. You see, there is always a silver lining.

I mention all this because the situation for NHS practitioners is likely to get rapidly worse now that we have been dragged into this bureaucratic whirlwind. Many of you are dealing with people at your PCT who know nothing about dentistry, know nothing about running a business, and know nothing about putting patients' interests first. This is not true of all PCTs of course, but it is true of many. The time gets ever closer where privatisation becomes a matter of survival. This is not to say that private practices will be immune to the whirlwind, far from it. You will however have a much greater degree of freedom and self determination, especially if your practice is fully systemised. And if your practice is not systemised, may I ask you why not?

There are a lot of dentists out there who have now simply become UDA hunters. All that matters is making the UDAs, to the detriment of the relationship with their patients. They are slowly and steadily killing their own goodwill. Not the goodwill that forms part of the practice value, but the goodwill with the people who they may one day need to try and convert to private dentistry. Do you really want to turn off all the people that will represent your future income? You could well easily be delivering short term gain, but you will be storing up long term pain.

There is another, even bigger challenge facing those who think they can stay in the NHS in my view. There is no longer the money for it in the long run. The Government can no longer afford the NHS, and must amputate bits off to keep the main body alive. Ninety billion pounds a year, as well as goodness knows how much on various IT schemes and initiatives to try and improve it (and which seem to only make the situation worse). This is not so much the fault of government; it is a fault of our ever more complex society, although it is not just complexity that increases the NHS bill. There are more people, living longer and getting sicker due to a host of factors. The NHS as a whole does little to combat the causes of disease; instead it looks to treat the results. But factored into this is has to be that as more and more people get sick, there is an ever increasing demand for newer and better drugs, treatments and therapies to make them well again. It is not acceptable for the health of the nation to decline in 
our modern society. But as the process of developing these new treatments gets more complex, so the returns delivered by said treatments diminishes, at an ever increasing cost. In 20 years we may even be able to grow brand new organs for people: do you think the state will be able to afford that? Let's put it this way, can the state afford for everyone to have access to a specialist endodontist armed with all the latest techniques? You know the answer to that.

Increasing complexity is straining the treasury coffers at a time when tax revenue is under threat due to a number of factors. North Sea Oil production peaked in 1999, and the UK is now a net importer of oil which costs the country money. Falling high street sales with rising national and personal debt, capped off by rising unemployment create a huge sucking sound within the bowels of number 11 Downing Street. Exports, while presently robust, may well see a marked decline as the recession in the United States bites ever deeper and all the time public expenditure continues to rise because it is political suicide for it not to. Huge resources are used to obtain diminishing returns so as to create political sound bytes. Something, somewhere has to give. Somehow I don't think it will be the provision of cancer care or your MP's pension.

Those who fail to learn the lessons of history usually make the same mistakes our ancestors made. To remain as self employed, independent contractors, GDPs will have no option but to look towards the private sector. The majority of us cannot survive within the new NHS, not if we want to stay healthy and happy. You will be forced into the realms of an ever decreasing UDA value, while being required to do more paperwork and cost cutting. Plus, of course, you will have to see more patients, with less and less ability to select them. As the PCTs' power grows, so your ability to control what goes on in your practice will die. In the years to come you will effectively give the PCT your practice. You will lose virtually all say in how it is run (look at the dental contract monitoring toolkit) while being blessed with all the financial risk. Couple this with the threat of having your funding removed in the wink of an eye, and you will see how no independent business can buy this. The NHS doesn't think twice about shutting whole hospital wards down - your little dental practice will have even less consequence.

Unless there are drastic changes, our future lies in the realms of self determination. You can set your own fees, treat the patients you want to treat and do the dentistry you want to do. Or you can stay in the NHS and ride the whirlwind. The choice is yours. 